\title{
Personality superfactors and healthy behaviors of professional athletes
}

\author{
Mariusz Lipowski ${ }^{1 \cdot A, B, C, D, E, F, G}$, Łucja Bieleninik ${ }^{2 \cdot D, E, F}$ \\ 1: Department of Health Psychology, Gdansk University of Physical Education and Sport, Gdansk, Poland \\ 2: GAMUT, Uni Research Health, Bergen, Norway
}

\section{BACKGROUND}

Personality traits seem to be excellent predictors of starting, continuing and discontinuing physical activity. Moreover, they constitute an important determinant of health-seek ing behaviors. Therefore, consideration of personality-related variables may be helpful in explaining either motivation of athletes or the goals they achieve.

\section{PARTICIPANTS AND PROCEDURE}

The study included 1229 individuals, among them 532 active athletes and 697 persons with no history of competitive sporting activities. The group of sportspersons included 286 team sport athletes, 124 representatives of individual sport disciplines and 125 combat sport athletes.

\section{RESULTS}

The athletes were found to have moderate levels of all analyzed personality dimensions. Multiple regression analysis showed that personality traits explained $46 \%$ of variance in the level of Positive Psychological Attitudes $(F=4.0$, $p=0.009)$ and $36 \%$ of variance in the level of Health Practices $(F=2.7, p=0.043)$ presented by female combat sport athletes. Personality profile explained $30 \%$ of variance in the level of Proper Nutrition Habits $(F=7.8, p<0.001)$ and $40 \%$ of variance in Positive Psychological Attitudes $(F=11.2$, $p<0.001)$ of male combat sport athletes. Personality profile explained $38 \%$ of variance in the level of Proper Nutrition Habits $(F=7.2, p<0.001)$ and $30 \%$ of variance in Positive Psychological Attitudes $(F=5.1, p=0.001)$ presented by men who practiced individual sport disciplines.

\section{CONCLUSIONS}

Our study confirmed that the personality super-factors are associated with health-seeking behaviors of athletes regarding proper nutrition habits, positive psychological attitudes and health practices.

\section{KEY WORDS}

physical activity; Big Five; Proper Nutrition Habits; health practices; martial arts 


\section{BACKGROUND}

Competitive sport is not limited to participation in training and competition, but also represents a specific lifestyle. This lifestyle should be characterized by particular care for health and physical condition. However, the slogan "Sport equals health" refers rather to recreational sport activities and healthoriented training. The term "training" is typically associated with competitive sports, and its effects are evaluated in the context of the results achieved and medals won. Undoubtedly, both competitive and health-oriented trainings are associated with psychophysical effort. However, competitive training differs from the recreational one, mostly in terms of predefined goals. Willing to become faster, jump higher, be stronger (from Latin citius, altius, fortius), and overcoming training loads are not enough; success in modern sport is a result of hard work starting in early childhood. Many researchers analyzing factors determining regular participation in physical exercise postulate a multidimensional and general approach to the question of starting, continuing and discontinuing physical activity (see: Dishman \& Sallis, 1994; Lipowski, 2006). Furthermore, health-seeking behaviors are determined by personality traits and goals defined by an individual (Kinnunen et al., 2012). Consideration of personality-related variables may be helpful in explaining the phenomenon of resuming purposeful activities despite the presence of obstacles, such as fatigue, need for change, presence of alternative goals, interim opportunities and attractive situations unrelated to a predefined objective (Zaleski, 1991).

Recently, there has been growing interest in personality-related determinants of involvement in healthoriented physical activity (see: Goodwin \& Friedman, 2006; Lipowski, 2006). It is noteworthy that recreational physical activity may be undertaken due to various reasons, both associated with health-seeking behaviors (Lipowski, 2006) and pathologically driven, e.g. in the course of anorexia (Bratland-Sanda et al., 2010) or the so-called "obligatory run" syndrome (Hamer \& Karageorghis, 2007). The unquestioned association between physical activity and health was highlighted in yearly prophylactic guidelines of the World Health Organization (2012). According to these guidelines, activities aimed at increasing physical activity level should constitute one crucial objective of health promotion.

However, regular participation in competitive sports is directly and indirectly associated with a number of health threats. The first group of threats includes use of various doping or psychoactive substances. Yusko, Buckman, White, and Pandina (2008) found that American college student athletes drink alcohol markedly more often than their non-athlete peers. A similar tendency was also documented in studies conduct- ed in Europe (Łuszczyńska, 2011). This phenomenon can be explained by the model based on three psychological attitudes to alcohol drinking: expectation for positive reinforcement, better functioning in a group and support in coping with stress associated with practicing sports (Martens, Dams-O’Connor \& Klimer, 2007). Drinking alcohol may give an athlete the illusion of better functioning, controlling emotions and having high quality social relationships. Interestingly, a study conducted in New Zealand showed that team sport athletes are more prone to harmful drinking than persons practicing individual sports (O'Brien, Hunter, Kypri \& Ali, 2008). However, similar tendencies were not documented with regards to cigarette or marijuana smoking, both significantly less prevalent among individuals involved in regular training than among persons who do not participate in sport (Yusko et al., 2008).

The issue of athletes' use of harmful substances is inevitably associated with doping, i.e. the use of prohibited substances to enhance one's sport performance. It is difficult to determine the prevalence of doping in sport as respective legislation undergoes constant changes and athletes using doping will obviously not declare it to the public. Unfortunately, a restrictive anti-doping policy is rarely accompanied by educational activities familiarizing sportspersons with harmful health effects of prohibited substances. As a result, many athletes believe that doping substances are harmless and their effect is limited solely to enhancing one's performance. The results of a survey conducted among 198 Olympic athletes are alarming, since as many as 195 declared that they would use doping if guaranteed of not being caught (Bamberger \& Yaeger, 1997). Even more surprising is the fact that more than half of the respondents declared that they would take a performance-enhancing substance if guaranteed of winning all competitions and then dying due to side effects. These results stimulate reflection on the pressure for success and system of values presented by athletes participating in the survey.

Injuries and contusions experienced by athletes constitute another argument for harmful consequences of participation in competitive sports. Previous studies documented a relationship between psychological stress experienced during competition and risk of serious injury (Blecharz, 2008). An athlete exposed to stress shows enhanced muscle tone and frequently experiences muscular contractions which very often lead to injury resulting from an acute confrontation with a competitor, or inappropriate positioning of a limb; such injuries undoubtedly could be avoided if the muscles were relaxed and the athlete moved more flexibly. Moreover, psychological stress associated with a competition impairs attention and perception of dangerous situations, thus increasing the risk of injury. 
Exercise addiction constitutes another issue related to health threats of competitive sporting. The typical signs of exercise addiction include obsessive thinking about exercise and feeling of guilt or even fear when skipping a planned training session (Pasman \& Thompson, 1988). Moreover, one develops a mechanism of increased tolerance which is also characteristic for other types of addiction - after a certain amount of time previous training loads are perceived as insufficient and thus constantly increased in order to satisfy an athlete. This inevitably leads to uncontrolled, too intensive exercising. Moreover, competitive sporting is associated with increased risk for eating disorders. It is noteworthy that participation in competitive sports was shown to be associated with higher incidence of eating disorders, mostly anorexia and bulimia (Euszczyńska, 2011). Therefore, many authors emphasize the association between involvement in physical activity and care for attractive appearance (Lipowski, Bulinski \& Krawczynski, 2009; Johnson, Fallon, Harris \& Burton, 2013). Recently, the body, its appearance and capability have gained growing importance, and physical personality is frequently equated with "public personality" (Fox, 1997) as a subject of consumption and social turnover. More than ever, the human body is inevitably associated with personality, and its social role is becoming difficult to ignore for both individuals and researchers. Therefore, physical appearance is gaining importance as a determinant of human functioning. A growing body of evidence suggests that Northern American communities and citizens of other Western countries exert a considerable effect on our opinions regarding standards of body esthetics, so important already for athletes from Ancient Greece. This is reflected not only by excessive striving for strengthening one's body, but also improving one's physical fitness and health. Not surprisingly, many previous studies have revealed an association between physical attractiveness and happiness (Robles, 2009; Gumble \& Carels, 2012). However, excess care for one's appearance, body weight concerns and other similar behaviors are not only a result of social pressure. It was shown that people representing certain personality types are more prone to suggestions of others regarding their appearance (Swami, Hadji-Michael \& Furnham, 2008).

A growing number of authors emphasize associations between personality-related variables and the level of subjective satisfaction with life (Staudinger, Fleeson \& Batles, 1999). Therefore, the Five Factor Model by Costa and McCrae (1992), according to which personality is stable throughout lifetime, is quite a popular concept. The dimensions (factors) identified by the authors of this model, i.e. neuroticism, extraversion, openness to experience, agreeableness and conscientiousness, are associated with subjective sense of psychological wellbeing. Previous studies documented an inverse association between neuroticism and satisfaction, and a positive correlation between extraversion, openness to experience and overall satisfaction with life (Costa, McCrae \& Norris, 1981). As mentioned above, the model proposed by Costa and McCrae (1992) assumes relative stability of personality traits; therefore, these traits would be an independent factor modulating one's satisfaction with life (Mądrzycki, 1996). In contrast, physical attractiveness, particularly an athletic physique, although it also improve one's satisfaction, can be modified, for example by practicing sports.

In view of the above, one may ask about a personality profile that modulates health-seeking behaviors of competitive athletes, and the potential effect of gender on this relationship. Also the question of whether the personality super-factors exert different effects on health-seeking behaviors of individuals who do not practice sport is worth explaining. One may assume that the personality profile of athletes determines their health-seeking behaviors, and this relationship is moderated by either gender or type of sport discipline. On the basis of published data one can hypothesize that neuroticism may exert a strong positive effect on proper nutrition habits of female athletes, and greater extraversion of male athletes is associated with a lower level of prophylactic behavior.

\section{PARTICIPANTS AND PROCEDURE}

The study included 1229 individuals, among them 532 active competitive athletes and 697 persons with no past or present history of competitive sporting. The group of sportspersons included 147 female and 385 male athletes, and the non-athlete group comprised 262 women and 435 men. The training experience of the athletes ranged between 2 and 21 years $(M=8.9, S D=4.3)$, and their age range was $16-30$ years $(M=21.8, S D=3.8)$, thus promoting optimal achievements in sports. The group included team sport athletes $(N=286$, football, handball, basketball and ice hockey), persons who practiced individual sports $(N=124$, figure skating, rhythmic gymnastics and bodybuilding) and combat sport athletes $(N=125$, kickboxing, taekwondo, karate and fencing). The controls were between 16 and 30 years of age $(M=21.4$, $S D=4.5$ ); thus the groups were matched for age.

All the participants were examined with Health Behavior Inventory and NEO-Five Factor Inventory (NEO-FFI).

The Health Behavior Inventory (HBI) by Juczyński (2001) is used for evaluation of involvement in healthseeking practices. The answers are analyzed in four categories of health-seeking behaviors: Proper Nutrition Habits, Prophylactic Behavior, Health Practices and Positive Psychological Attitudes. 
The NEO-Five Factor Inventory (NEO-FFI) by Costa \& McCrea, in the Polish adaptation by Zawadzki, Strelau, Szczepaniak, and Śliwińska (1998), determines principal personality dimensions, the so-called Big Five, i.e. Neuroticism, Extraversion, Openness to Experience, Agreeableness and Conscientiousness.

\section{RESULTS}

Statistical analysis was conducted with Statistica 10 software (General Linear Models, Multiple Regression, Multi-Factor ANOVA, Pearson's $r$ correlation).

\section{PERSONALITY PROFILES OF ATHLETES AND NON-ATHLETES}

Personality profile analysis revealed that athletes scored moderately in terms of all the studied dimensions (Figure 1).

The athletes were found to have lower levels of neuroticism than female $(t=4.4, p<0.001)$ and male non-athletes $(t=4.3, p<0.001)$. Whereas female and male non-athletes did not differ significantly in terms of their Neuroticism levels, female athletes had slightly lower levels of Neuroticism than did male sportsmen $(p=0.028)$. After stratifying the athletes according to the type of sports discipline, female combat sport athletes were characterized by lower levels of Neuroticism than their male counterparts $\left(M_{\mathrm{k}}=3.7\right.$, $\left.S D_{\mathrm{k}}=2.2, M_{\mathrm{m}}=4.9, S D_{\mathrm{m}}=1.6, t=3.5, p=0.001\right)$. The level of Neuroticism in athletes was associated with neither age nor training experience. In contrast, an age-related decrease in Neuroticism level was documented in the case of female $(r=-0.40, p<0.001)$ and male non-athletes $(r=-0.33, p<0.001)$.

Female and male athletes had similar levels of Extraversion, higher than in their female $(t=4.3, p<0.001)$ and male $(t=5.4, p<0.001)$ non-athlete counterparts. We did not document a significant effect of gender on the level of Extraversion, either among athletes or in non-athletes. Furthermore, the levels of this trait did not differ significantly when stratified according to gender and type of practiced sport discipline. Moreover, the levels of Extraversion did not show significant associations with age and training experience.

Compared to their non-athlete counterparts, male athletes showed slightly, albeit significantly, higher levels of Openness to Experience $(t=2.3, p=0.019)$. While male and female non-athletes did not differ significantly with regards to their Openness to Experience, female athletes presented higher levels of this trait than did the male sportsmen $(t=2.8, p=0.005)$.

The level of Agreeableness in male athletes was significantly higher $(t=6.1, p=0.005)$ than in male non-athletes. This finding is somewhat surprising as sport by default represents a kind of competition; perhaps our athletes become partially socially addicted. Moreover, we found that female athletes had lower levels of Agreeableness than did their male peers $(t=2.2, p=0.032)$. In contrast, gender did not influence Agreeableness levels in the group of non-athletes.

We did not observe a significant effect of gender on Conscientiousness in our athletes. The lowest levels of Conscientiousness, significantly lower than in male athletes $(t=5.3, p<0.001)$ and female non-athletes $(t=3.7, p<0.001)$, were documented among male non-athletes.

The levels of Conscientiousness differed significantly when the athletes were stratified according to practiced sport discipline $(F=19.1, p<0.001)$. Combat sport athletes showed the highest levels of this trait $(M=7.7, S D=2.2)$, significantly higher than in the remaining groups $(p<0.001)$. In turn, we did not document significant differences in the Conscientiousness of team sport athletes $(M=6.5, S D=1.9)$ and persons practicing individual sports $(M=6.6, S D=1.9)$. Furthermore, the level of Conscientiousness was not significantly associated with the age of athletes or non-athletes. However, the Conscientiousness of combat sport athletes was correlated with their training experience $(r=0.36, p=0.002)$.

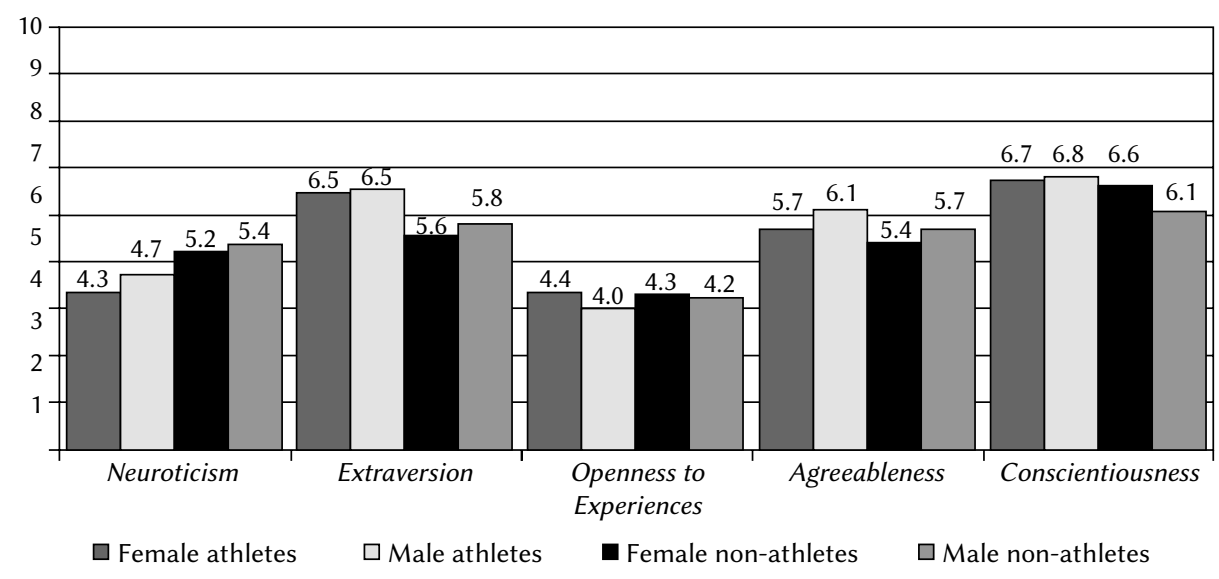

Figure 1. Personality profiles of female and male athletes and non-athlete controls (sten values). 


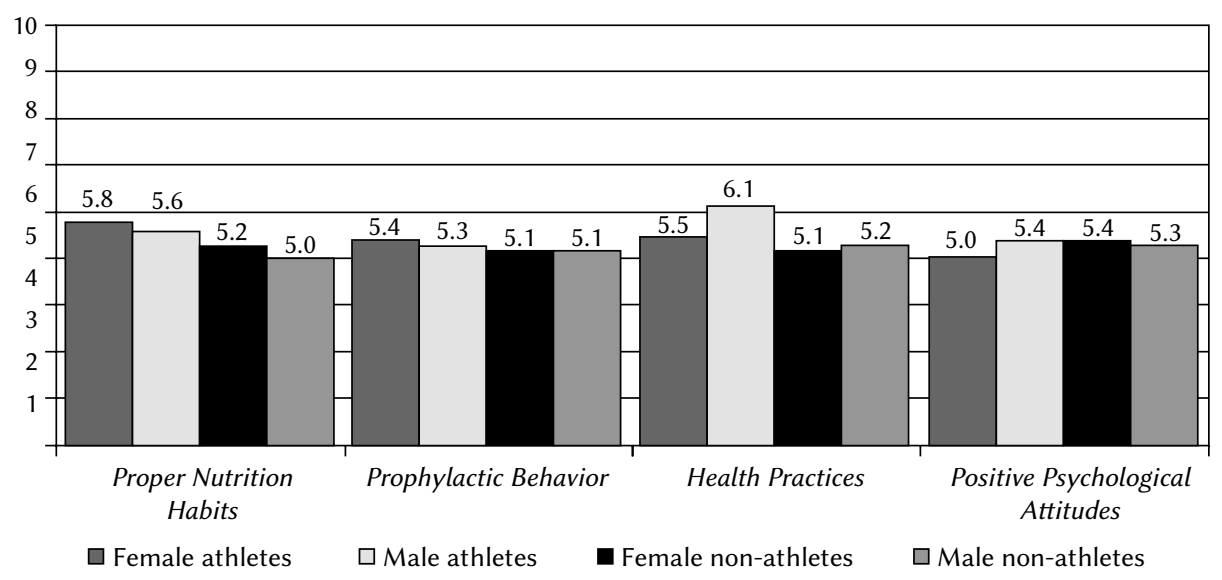

Figure 2. Health-seeking behavior profiles of female and male athletes and non-athletes (sten values).

\section{HEALTH-SEEKING BEHAVIORS OF ATHLETES AND NON-ATHLETES}

The athletes showed a slightly, albeit significantly $(t=4.6, p<0.001)$, higher level of Proper Nutrition Habits than did their non-athlete counterparts (Figure 2). The intergroup differences between the athletes and non-athletes were also observed in subgroup analysis of both women $(t=2.9, p=0.004)$, and men $(t=4.3$, $p<0.001)$. In turn, the levels of Proper Nutrition Habits of women and men did not differ significantly, either among athletes or in non-athletes.

After stratifying the athletes according to practiced sport discipline and gender, we found that male combat sport athletes displayed higher levels of Proper Nutrition Habits $(M=6.0, S D=1.8)$ than did men who practiced individual $(M=5.5, S D=2.2)$ and team sports $(M=5.4, S D=1.8)$; the significance of intergroup differences was confirmed by ANOVA $(F=3.9, p=0.020)$. Moreover, male combat sport athletes were the only group showing a significant association between the level of Proper Nutrition Habits and training experience (but not age) $(r=0.31, p=0.002)$. This significant, albeit relatively weak, association may be interpreted in terms of the relationship between training experience and controlling weight in order to fit into a given weight category. We did not observe significant correlations between Proper Nutrition Habits, age and training experience in any other cluster defined according to gender, participation in sport or type of sport discipline.

Our athletes presented with moderate levels of Prophylactic Behavior, which did not differ significantly when compared to their non-athlete counterparts. Female combat sport athletes showed higher levels of Prophylactic Behavior compared to men practicing sports from this group $\left(M_{\mathrm{k}}=6.4, S D_{\mathrm{k}}=2.3\right.$, $\left.M_{\mathrm{m}}=5.0, S D_{\mathrm{m}}=1.6, t=2.9, p=0.004\right)$. Martial arts are known to be highly predisposing to injury, mostly due to the fact that they require direct, ag- gressive contact with a competitor. Therefore, one can assume that our male combat sport athletes took less care for protection of their health than did the sportswomen. After stratifying our participants according to the type of sport discipline, we found that athletes practicing individual sports had the lowest levels of Prophylactic Behavior $(M=4.6$, $S D=1.8)$, significantly lower than in the case of combat sports $(M=5.3, S D=1.9)$ and team sport athletes $(M=5.6, S D=1.9)$; the significance of these intergroup differences was confirmed by analysis of variance $(F=11.1, p<0.001)$. A significant inverse relationship between the level of Prophylactic Behavior and training experience (but not age) was observed solely among women practicing individual sports $(r=-0.32, p=0.012)$. Therefore, one may ask if more experienced female athletes take less care about prevention; perhaps it is greater training experience which promotes (unjustified) non-adherence to prophylactic guidelines. The levels of Prophylactic Behavior did not correlate significantly with either age or training experience in any of the clusters defined according to gender, participation in sport or type of sport discipline.

Compared to their non-athlete counterparts, the sportspersons presented significantly higher levels of Positive Psychological Attitudes $(t=6.2, p<0.001)$. The higher levels of Positive Psychological Attitudes of athletes likely reflected, as previously mentioned, greater motivation of success and ability to cope with stress. After stratifying the results according to gender, the level of Positive Psychological Attitudes was the highest among male athletes; the level of Positive Psychological Attitudes in this group was significantly higher than in male non-athletes $(t=6.2$, $p<0.001)$ and female athletes $(t=3.8, p<0.001)$. Therefore, a higher level of Positive Psychological Attitudes seems to be a specific feature of male athletes. Only $9.5 \%$ of our athletes showed low levels of Positive Psychological Attitudes, which can be interpreted as a favorable prognostic factor for future suc- 
cess. In contrast, the fraction of non-athletes showing a low level of Positive Psychological Attitudes was twice as high as among the athletes (21.9\%). After stratifying the results according to the type of practiced discipline and gender, we found that the level of Positive Psychological Attitudes among male combat sport athletes $(M=6.5, S D=1.8)$ was significantly higher than in team sport athletes $(M=6.1, S D=1.7)$ and individuals practicing individual sports $(M=5.1$, $S D=1.9$ ); the significance of these intergroup differences was confirmed by analysis of variance $(F=3.7$, $p=0.025)$. The level of Positive Psychological Attitudes of female non-athletes increased significantly with age $(r=0.33, p<0.001)$. Male combat sport athletes were the only group of sportspersons who showed a significant association $(r=0.36, p=0.002)$ between the level of Positive Psychological Attitudes and training experience (but not age).

Both athletes and non-athletes presented with similar, moderate levels of Health Practices. Women and men from either group did not differ significantly in terms of the analyzed parameter. After stratifying the results of the sportspersons according to the type of practiced sport and gender, we found that female combat sport athletes had a significantly higher level of Health Practices $(M=5.8, S D=1.9)$ than their counterparts who practiced team $(M=4.7, S D=1.6)$ and individual disciplines of sports $(M=5.9, S D=1.8)$; the significance of these differences was confirmed by analysis of variance $(F=4.0, p=0.020)$. One should note the lack of significant differences in the levels of Health Practices among men representing various sport disciplines. Furthermore, the level of Health Practices did not correlate significantly with age and training experience of our participants, including after stratification according to gender, participation in sport or type of sport discipline.

\section{PERSONALITY PROFILE VS. HEALTH-SEEKING BEHAVIORS OF ATHLETES}

Multiple regression analysis of personality profile, as an independent variable explaining the level of health-seeking behaviors (dependent variable), showed that personality traits explained $46 \%$ of variance in the level of Positive Psychological Attitudes ( $F=4.0, p=0.009)$ and $36 \%$ of variance in the level of Health Practices $(F=2.7, p=0.043)$ shown by female combat sport athletes (Figure 3).

Multiple regression analysis revealed that personality profile (independent variable) explained $30 \%$ of variance in the level of Proper Nutrition Habits $(F=7.8, p<0.001)$ and $40 \%$ of variance in Positive Psychological Attitudes $(F=11.2, p<0.001)$ of male combat sport athletes (Figure 4).

Furthermore, the personality profile (independent variable) explained $38 \%$ of variance in the level of Proper Nutrition Habits $(F=7.2, p<0.001)$ and $30 \%$ of variance in Positive Psychological Attitudes ( $F=5.1$, $p=0.001)$ shown by men who practiced individual sport disciplines (Figure 5).

Apart from the abovementioned association, we revealed a number of significant correlations between personality traits and level of health-seeking behaviors. Higher Neuroticism scores of female combat sport athletes were associated with lower levels of Positive Psychological Attitudes $(r=-0.62, p<0.001)$ and Health Practices $(r=-0.45, p=0.012)$. Significant relationships between the level of Neuroticism and health-seeking behaviors were also documented in women and men who practiced individual sports: higher Neuroticism scores were reflected by lower levels of Proper Nutrition Habits $\left(r_{\mathrm{k}}=-0.38, p_{\mathrm{k}}=0.003\right.$, $\left.r_{\mathrm{m}}=-0.37, p_{\mathrm{m}}=0.032\right)$ and Positive Psychological Attitudes $\left(r_{\mathrm{k}}=-0.43, p_{\mathrm{k}}=0.001, r_{\mathrm{m}}=-0.38, p_{\mathrm{m}}=0.028\right)$. Furthermore, greater neuroticism was associated

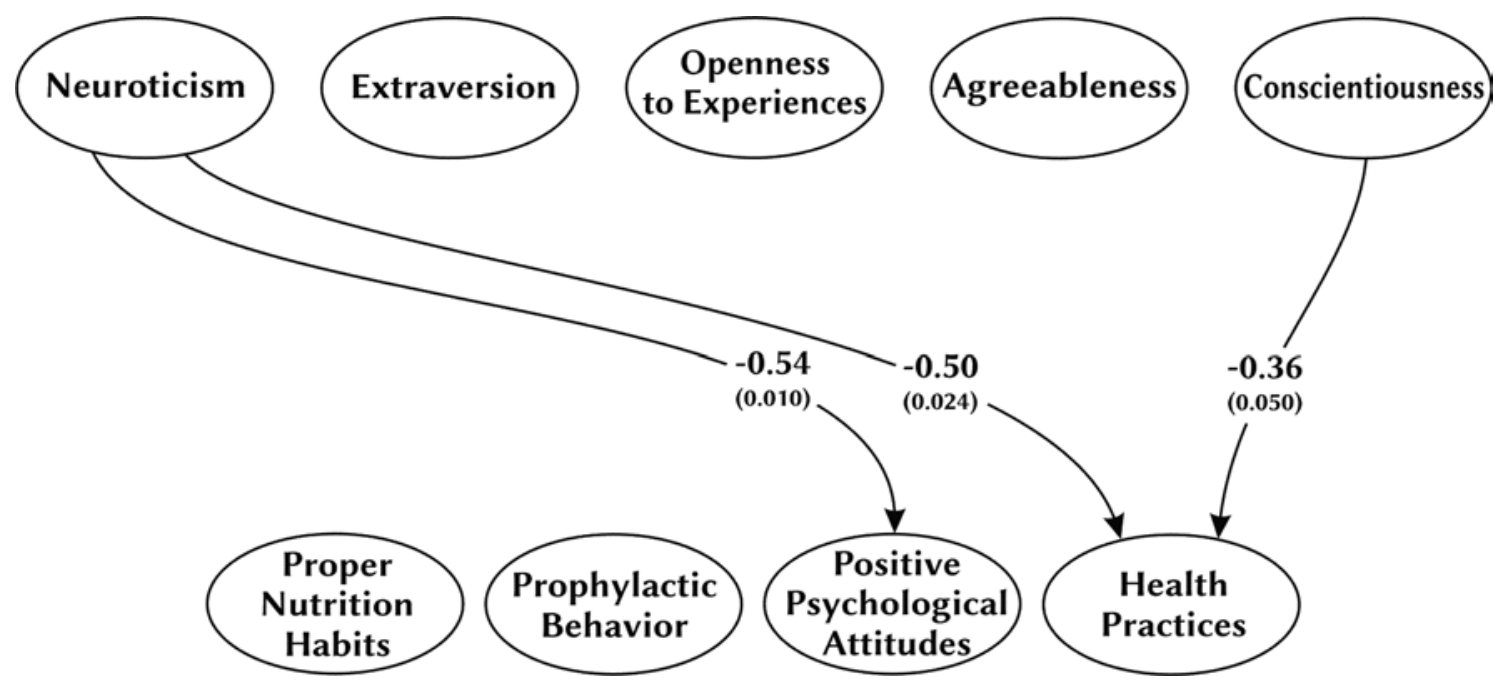

Figure 3. Results of multiple regression analysis for female combat sport athletes. 


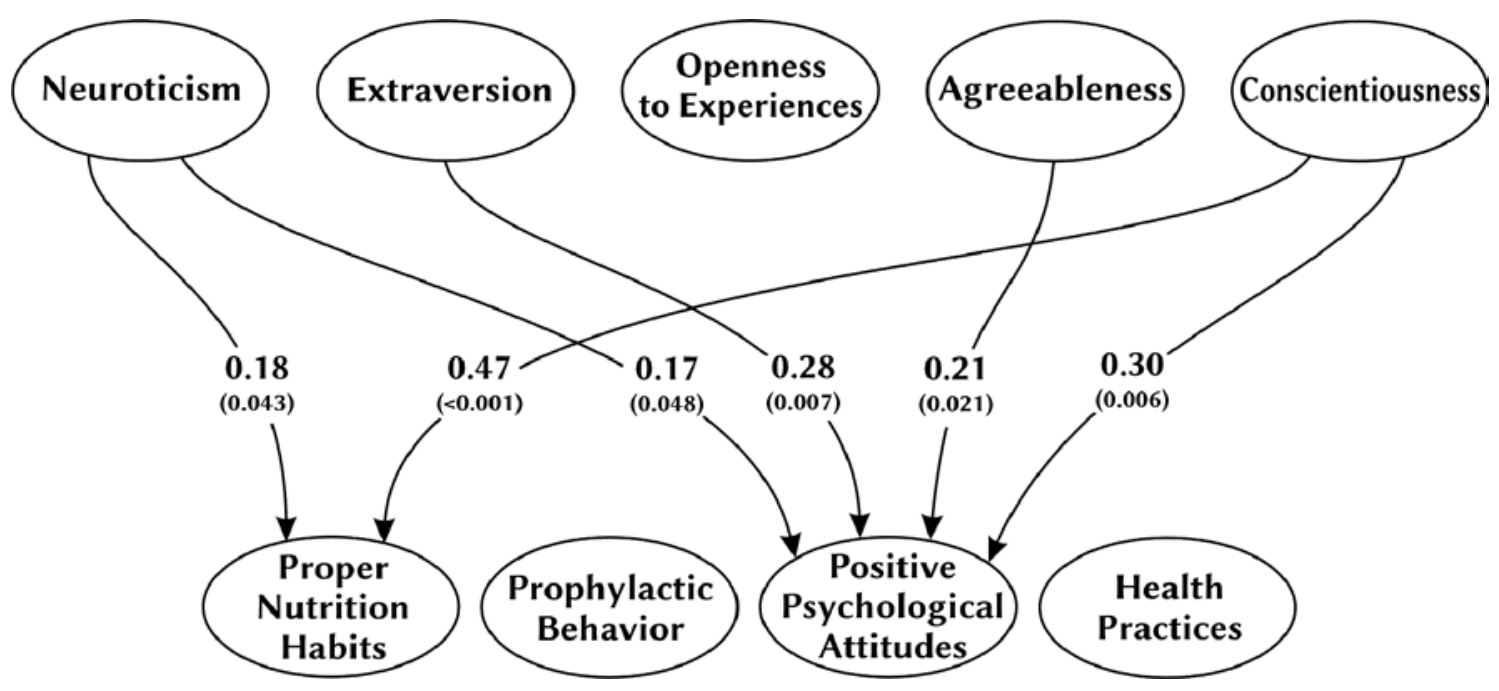

Figure 4. Results of multiple regression analysis for male combat sport athletes.

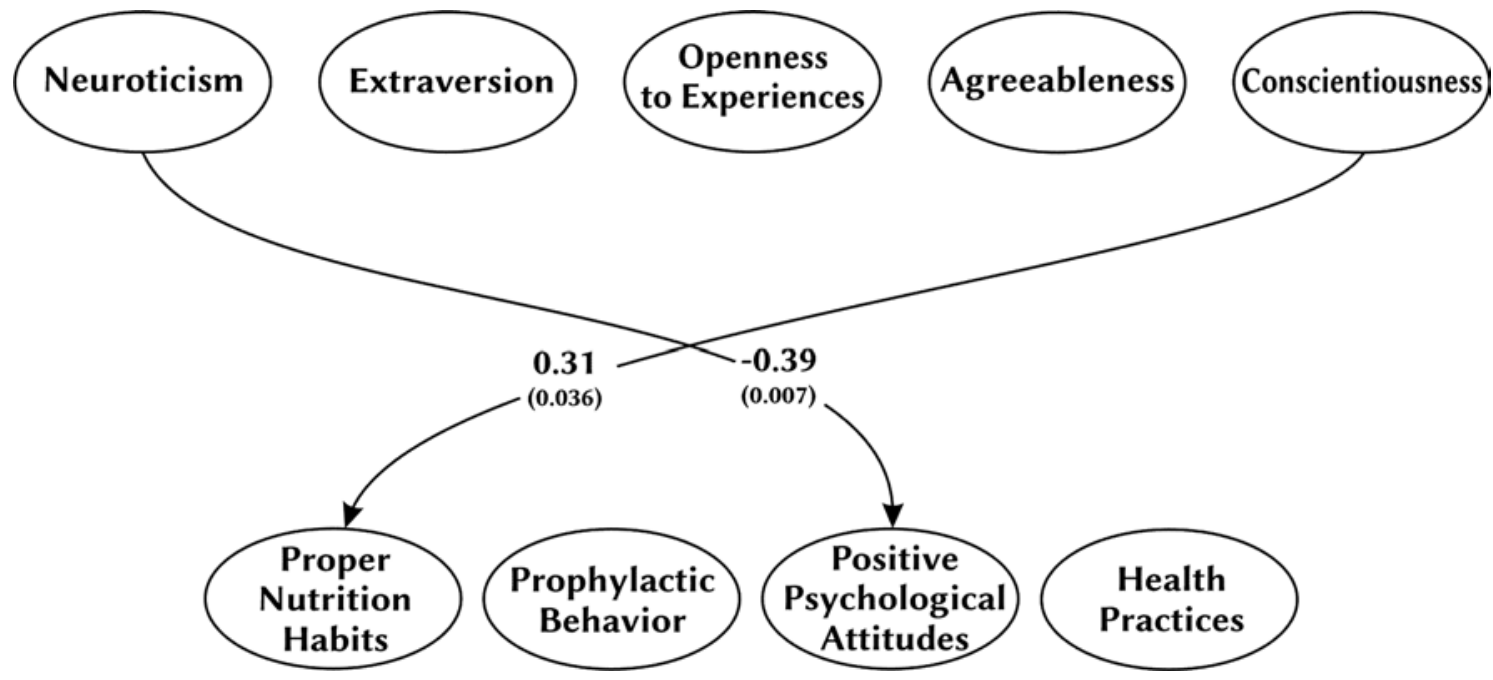

Figure 5. Results of multiple regression analysis for men practicing individual sport disciplines.

with a lower level of Positive Psychological Attitudes presented by male $(r=-0.39, p<0.001)$ and female non-athletes $(r=-0.48, p<0.001)$. In turn, the levels of Positive Psychological Attitudes of female ( $r=0.36$, $p<0.001)$ and male non-athletes $(r=0.32, p<0.001)$ increased proportionally to the Extraversion scores. A similar association was also observed in the case of male combat sport athletes $(r=0.48, p<0.001)$. Moreover, greater extraversion was associated with higher levels of Proper Nutrition Habits of men practicing individual sport disciplines $(r=0.45, p=0.003)$. Combat sport athletes showed a significant correlation between Openness to Experience, Proper Nutrition Habits $(r=0.33, p=0.001)$ and Positive Psychological Attitudes ( $r=0.34, p=0.001)$. Furthermore, both female $(r=0.44, p=0.015)$ and male combat sport athletes $(r=0.38, p<0.001)$ showed significant correlations between Agreeableness and Positive Psychological Attitudes. Moreover, Agreeableness scores were correlated significantly with the level of Proper
Nutrition Habits $(r=0.34, p=0.049)$ and Prophylactic Behavior $(r=0.36, p=0.039)$ of men practicing individual sports. Greater Conscientiousness of male combat sport athletes was associated with higher levels of Proper Nutrition Habits $(r=0.49, p<0.001)$ and Positive Psychological Attitudes $(r=0.53, p<0.001)$. Moreover, Conscientiousness correlated significantly with the level of Prophylactic Behavior $(r=0.38$, $p=0.003)$ and Positive Psychological Attitudes $(r=0.39$, $p=0.002)$ of women practicing individuals sport disciplines, as well as with the level of Proper Nutrition Habits in their male counterparts $(r=0.51, p<0.001)$.

\section{DISCUSSION}

The described super-factors form various configurations that can be interpreted either in the context of personality profile or in the functional context. We used the former approach to characterize our athletes 
and identify their general personality profile. Our findings are consistent with the results of previous studies. Tok (2011) conducted a comparative analysis of individuals practicing high-risk sports (e.g. scuba diving, free diving, paragliding, rafting, rock climbing and surfing) on a regular basis, and persons who neither practiced competitive sports nor were involved in high-risk disciplines on a recreational basis. They found that participants from the former group scored significantly higher in terms of extraversion and openness to experience, and presented with lower levels of neuroticism and conscientiousness. Also Kajtna, Tušak, Barić and Burnik (2004) reported that high-risk sport athletes (alpinists, sky divers, paragliders, white-water kayakers, downhill mountain-bikers, motocross riders, downhill skiers and ski jumpers) differed from non-risk sportsmen (swimmers, track athletes, sailors, flat-water kayakers, rowers, Nordic skiers, sport climbers, karatekas) and individuals from the non-athletic group in terms of such personality traits as energy, acceptability, conscientiousness, emotional stability and openness. High-risk sport athletes displayed the highest levels of all these traits, followed by other sportsmen and non-athletes; significant intergroup differences were documented in the case of energy, conscientiousness, emotional stability and openness. Irrespective of the group, the levels of openness were the highest, followed by conscientiousness, acceptability and energy. Noticeably, the non-risk sportsmen presented a higher level of openness than did the high-risk sport athletes.

Many previous studies have shown that athletes exhibit higher levels of extraversion (Tok, 2011), energy (Kajtna et al., 2004) and sensory seeking (Aluja, García \& García, 2003) than non-athletes. Extraverts are characterized by high levels of activity, energy, stimulation, excitement and risk seeking. Moreover, athletes with high levels of extraversion show a tendency to responding with positive emotions and general good mood, which enables them to retain optimism even in the case of failure, and strive for their predefined objectives. Our athletes showed moderate, but still higher than in the controls, levels of Openness to Experience, which is consistent with the data published by Tok (2011). Actively seeking new stimulation, being one component of openness to experience, stimulates athletes to action. The sportspersons taking part in our study displayed moderate levels of Neuroticism; the levels of this trait in athletes were lower than in non-athlete controls, which is also consistent with Tok's (2011) findings. Our findings are vitally important from the viewpoint of functioning of an individual, as high neuroticism is generally associated with low resistance to psychological stress (Zawadzki, Szczepaniak \& Strelau, 1995), which in turn does not promote adaptation of athletes to competition. Kajtna et al. (2004) reported that athletes practicing high-risk sports are more emotionally stable than non-risk sportsmen and non-athletes. Also this finding is of vital importance as emotional stability allows sportspersons to maintain emotional control in either stressful or risky situations. Although our athletes showed moderate levels of Conscientiousness, the scores of male athletes were still higher than those of non-athlete controls. Kajtna et al. (2004) found that high-risk sportsmen show high levels of conscientiousness, the highest of all traits analyzed in the study conducted by these authors. Conscientiousness constitutes a crucial dimension of an athlete's personality, as it reflects the degree of organization, perseverance and motivation of an individual for goal-oriented activities. Persons characterized by high levels of conscientiousness present strong will, are motivated to activity and persevere in striving for their objectives. Therefore, athletes characterized by high levels of this trait are dutiful, show high levels of aspiration and strong motivation for success in life, greater capability of self-motivation to complete their tasks, as well as a tendency to meticulous analysis of a problem prior to making a decision and undertaking any action. Booth et al. (2013) found that a lower level of conscientiousness is associated with brain-tissue loss, a lower degree of fractional anisotropy and white matter hyperintensities; the authors interpreted these findings as an effect of personality on brain aging. Moreover, they suggested that stability of personality traits may influence the level of health-seeking behaviors and thus the condition of the brain throughout lifetime.

Analyzing the association between personality traits and health-seeking behaviors we identified a number of interesting relationships. We found that neuroticism is associated with health-seeking behaviors of athletes; higher levels of Neuroticism were associated with a decrease in Prophylactic Behavior, Proper Nutrition Habits and Positive Psychological Attitudes. Therefore, high neuroticism is unlikely to promote care for one's health. According to Bond and Feather (1988), a lower level of neuroticism is associated with more structured and purposeful actions; this suggests that neuroticism might also exert an unfavorable effect on the level of Positive Psychological Attitudes of our participants. Furthermore, neuroticism is a predictor of one's health status since it is associated with health-oriented behaviors and attitudes (Zawadzki et al., 1998). We revealed a significant correlation between Extraversion and the levels of health-seeking behaviors presented by non-athletes and combat sport athletes: higher Extraversion scores were associated with higher levels of Positive Psychological Attitudes of both women and men. In the case of athletes practicing individual sports, greater extraversion promoted proper nutrition habits, and greater agreeableness was associated with higher levels of Positive Psychological Attitudes, 
Proper Nutrition Habits and Prophylactic Behavior. Furthermore, we observed an association between Conscientiousness and health-seeking behaviors: higher Conscientiousness scores were reflected by higher levels of Proper Nutrition Habits and Positive Psychological Attitudes. Moreover, a higher level of Conscientiousness was associated with higher levels of Prophylactic Behavior and Positive Psychological Attitudes of women practicing individual sports, as well as Proper Nutrition Habits of male individual sport athletes.

The analysis of Health Behavior Inventory scores revealed that our athletes did not take enough care for their health in terms of Proper Nutrition Habits, Prophylactic Behavior, Positive Psychological Attitudes and Health Practices. Higher scores of the Health Behavior Inventory in female combat sport athletes and higher levels of Positive Psychological Attitudes among men practicing these disciplines are worth noting. These results documented among combat sport athletes may reflect the specific philosophy of martial arts, the fundamental principles of which are taught during training or constitute an essential component of an examination for a higher rank. Apart from physical training, in martial arts great emphasis is placed on development of "spirit". Therefore, aside from motivation for success, combat sport athletes have also performance goals defined. The performance goals focus on improvements and progress relative to one's own performance. The goals of this type are associated with mastering an activity or technique; the emphasis is placed on mastery, virtuosity in a given activity (Krawczyński, 2004). An athlete is focused on attaining proficiency in his/her task, rather than on his/her competitors. Apart from the performance goals, also the outcome goals, regarding attaining a specific standard (medal, result, championship) during a contest, can be identified, e.g. in individual sports. An athlete who defines his/her goals in this way is oriented on the result of a contest as a direct outcome of his/her skills. In contrast, combat sport athletes are focused rather on self-development of their body and spirit, and the result of a contest constitutes only a kind of feedback, inspiring them to further progress. Therefore, they take more care for their health, as a component of optimizing their general functioning. The abovementioned analyses may constitute a starting point and some kind of hypothesis stimulating further research in this matter. Also higher levels of Positive Psychological Attitudes presented by male team sport athletes are worth noting. Perhaps, this finding reflects specific personality traits of our participants or the fact that a team may serve as a kind of a resource in stressful task-oriented situations related to competition. Sharing the same objective, athletes provide themselves with greater social support. Consequently, one may expect the same in the case of female team sport athletes. Ex- tending our research with more in-depth personality profile analysis would be helpful in interpretation of these findings.

Analyzing the effect of personality profile on the scores of the Health Behavior Inventory, we identified specific personality traits that promoted health-seeking behaviors of our athletes. Functional interpretation refers to the role of personality traits in the adaptation of an individual to his/her environment; in the case of our study, functional interpretation pertained to an association between personality traits and health-seeking behaviors shown by the athletes. The analysis included three groups of sport disciplines practiced by our participants: team sports, individual sports and combat sports. Functional interpretation of the effect of personality traits on health-seeking behaviors was based on multiple regression analysis; only the models with at least $30 \%$ goodness of fit were considered satisfactory. We identified satisfactory regression models for female and male combat sport athletes as well as for men practicing individual sports. In contrast, none of the regression models explained variance in health-seeking behaviors of non-athletes. Analysis of regression showed that Neuroticism and Conscientiousness were principal independent determinants of health-seeking behaviors in the group of female combat sport athletes. Higher levels of these traits did not promote health-seeking behaviors of female athletes: greater neuroticism was associated with a lower level of Positive Psychological Attitudes, and higher levels of Neuroticism and Conscientiousness together were reflected by a lower level of Health Practices. These findings are consistent with the results published by Costa and McCrae (1992), who found that neuroticism is inversely correlated with both general satisfaction with life and subjective health status. Therefore, neuroticism does not seem to motivate women to participation in sport. Probably, this is associated with a "vicious circle": neurotic women perceive themselves as "psychophysically frail" and thus do not participate in sport, which further enhances their sense of "weakness". Presumably, breaking this "vicious circle" through active participation in sports, such as in the case of combat sport athletes, would result in development of mechanisms that reinforce self-esteem, which is typically low in neurotic individuals. Multiple regression analysis identified Neuroticism and Conscientiousness as the main independent variables determining health-seeking behaviors of males practicing combat sports. High levels of these traits promoted health-seeking behaviors of sportsmen. However, the effect of personality traits on health-seeking behaviors was weaker than in female athletes. Nevertheless, the personality super-factors exerted a more "complex" effect on health-seeking behaviors in male combat sport athletes: higher Neuroticism and Conscientiousness scores were reflected by higher levels 
of Proper Nutrition Habits in this group. Moreover, we detected significant associations between the levels of Positive Psychological Attitudes, Neuroticism, Extraversion, Agreeableness and Conscientiousness of male combat sport athletes; the higher were the levels of all these personality traits, the higher was the level of Positive Psychological Attitudes. Analysis of regression showed that Conscientiousness constitutes the principal predictor of health-seeking behaviors among athletes practicing individual sports. Greater conscientiousness was associated with a higher level of Proper Nutrition Habits in individuals from this group. In turn, greater neuroticism was reflected by a lower level of Positive Psychological Attitudes. Previous studies (Lipowski, 2012) showed that health-seeking behaviors of female athletes, such as daily sleep, reaction habits and physical activity, are also influenced by the level of optimism; greater pessimism was found to be associated with a lower level of positive health-oriented attitudes.

Surprisingly, we observed that greater conscientiousness did not promote health practices of female combat sport athletes. However, this observation should be interpreted in the context of higher levels of Neuroticism shown by sportswomen from this group. Under such circumstances, participation in sport may serve as a kind of antidote for greater emotional sensitivity of women, and caring too much for one's health would be considered as a manifestation of weakness. Consequently, female athletes may ignore the issue of health-oriented practices or even deny the presence of certain pathological symptoms. Moreover, the phenomenon documented in our study may be related to the fact that combat sports are typically considered to be male disciplines. Therefore, exposing feminine weakness is not reflected by positive reinforcement; thus, some female athletes do not adhere to medical recommendations. For example, one can frequently observe female athletes who participate in competition despite pain or injury. As this "heroine" syndrome may lead to more severe injuries, one should consider this personality-related aspect when planning training loads for female combat sport athletes.

\section{CONCLUSIONS}

Knowledge of psychological determinants of healthseeking behaviors can be used to modulate emotional processes of an athlete, both during a competition and during many years of training. Early detection of some "abnormalities" enables their correction through appropriate educational activities, which is reflected by optimization of the system: athlete's personality health-seeking behaviors - sport achievement. Data on health-seeking behaviors exhibited by sportspersons can be extremely useful for rational organization of a training process. Their knowledge can also be helpful in optimal exploitation of athletes' potential, improvement of their health-oriented activities, and maximizing sport achievements. Also the concept of personality type, based on the relationship between certain personality traits and health-seeking behaviors, can be useful during psychological diagnosis. Using this concept, one can predict with a given probability that representatives of a given sport discipline will perform health-seeking behaviors in a specific situation.

The present analysis of empirical material outlines perspectives for future research. One interesting direction of future studies is longitudinal analysis of the effects exerted by competitive sport on the development of an athlete's personality, from the first months of participation in training. An equally interesting research topic is periodic observation of changes in health-seeking behaviors and personality traits of athletes, resulting from participation in competitive sport and pedagogical influences of coaches and cooperating psychologists.

\section{References}

Aluja, A., García, Ó. \& García, L.F. (2003). Relationships among extraversion, openness to experience, and sensation seeking. Personality and Individual Differences, 35, 671-680. doi: http://dx.doi.org/ 10.1016/S0191-8869(02)00244-1.

Bamberger, M. \& Yaeger, D. (1997). Over the edge. Sports Illustrated, 14, 62-70.

Blecharz, J. (2008). Sportowiec w sytuacji urazu fizycznego [An athlete experiencing physical trauma]. Cracow: Wydawnictwo AWF.

Bond, M.J. \& Feather, N.T. (1988). Some correlates of structure and purpose in the use of time. Journal of Personality and Social Psychology, 55, 321-329.

Booth, T., Mottus, R., Corley, J., Gow, A.J., Henderson, R.D., Maniega, S.M. \& Deary, I.J. (2013). Personality, Health, and Brain Integrity: The Lothian Birth Cohort Study 1936. Health Psychology, 18, 18.

Bratland-Sanda, S., Sundgot-Borgen, J., Ro, O., Rosenvinge, J.H., Hoffart, A. \& Martinsen, E.W. (2010). "I'm not physically active - I only go for walks": physical activity in patients with longstanding eating disorders. International Journal of Eating Disorders, 43, 88-92.

Costa Jr, P.T. \& McCrae, R.R. (1992). Four ways five factors are basic. Personality and Individual Differences, 13, 653-665. doi: http://dx.doi.org/10.1016/ 0191-8869(92)90236-I.

Costa, P.T., Jr., McCrae, R.R. \& Norris, A.H. (1981). Personal adjustment to aging: longitudinal prediction from neuroticism and extraversion. Journal of Gerontology, 36, 78-85.

Dishman, R.K. \& Sallis, J.F. (1994). Determinants and interventions for physical activity and exercise. In: 
C. Bouchard, R.J. Shephard \& T. Stephens (eds.). Physical activity, fitness, and health. International proceedings and consensus statement (pp. 214-238). Champaign, IL: Human Kinetics.

Fox, K.R. (1997). The physical self and processes in self-esteem development. In: K.R. Fox (ed.). The physical self. From motivation to well-being (pp. 111139). Champaign, IL: Human Kinetics.

Goodwin, R.D. \& Friedman, H.S. (2006). Health status and the five-factor personality traits in a nationally representative sample. Journal of Health Psychology, 11, 643-654.

Gumble, A. \& Carels, R. (2012). The harmful and beneficial impacts of weight bias on well-being: the moderating influence of weight status. Body Image, 9, 101-107.

Hamer, M. \& Karageorghis, C.I. (2007). Psychobiological mechanisms of exercise dependence. Sports Medicine, 37, 477-484.

Johnson, P., Fallon, E.A., Harris, B.S. \& Burton, B. (2013). Body satisfaction is associated with Transtheoretical Model constructs for physical activity behavior change. Body Image, 10, 163-174.

Juczyński, Z. (2001). Narzędzia pomiaru w promocji i psychologii zdrowia [Instruments for measurements in health promotion and psychology]. Warszawa: Pracownia Testów Psychologicznych Polskiego Towarzystwa Psychologicznego.

Kajtna, T., Tušak, M., Barić, R. \& Burnik, S. (2004). Personality in high-risk sports athletes. Kinesiology, 36, 24-34.

Kinnunen, M.L., Metsapelto, R.L., Feldt, T., Kokko, K., Tolvanen, A., Kinnunen, U. \& Pulkkinen, L. (2012). Personality profiles and health: longitudinal evidence among Finnish adults. Scand Journal of Psychology, 53, 512-522.

Krawczyński, M. (2004). Gra dla zabawy czy gra dla zwyciężania - psychologiczne problemy uczestnictwa w sporcie dzieci i młodzieży [Game for fun or game to win - psychological problems associated with participation of children and adolescents in sport]. In: M. Krawczyński \& D. Nowicki (eds.). Psychologia sportu w treningu dzieci i mtodzieży [Sport psychology in training of children and adolescents] (pp. 73-83). Warszawa: Biblioteka Trenera.

Lipowski, M. (2006). Rekreacja ruchowa kobiet jako zachowanie prozdrowotne - uwarunkowania a motywy uczestnictwa [Physical activity of women as pro-health behavior - determinants and motives of participation]. Gdansk: Wydawnictwo: AWFiS.

Lipowski, M. (2012). Level of optimism and health behavior in athletes. Medical Science Monitor, 18, CR39-43.

Lipowski, M., Bulinski, L. \& Krawczynski, M. (2009). Physical activities among other types of health-related behaviour in people losing weight. Medical Science Monitor, 15, CR423-428.

Łuszczyńska, A. (2011). Psychologia sportu i aktywności fizycznej [Psychology of sport and physical activity]. Warszawa: Wydawnictwo Naukowe PWN.
Martens, M.P., Dams-O'Connor, K. \& Klimer, J.R. (2007). Alcohol and drugs use among athletes. Prevalence, etiology and interventions. In: G. Tenenbaum \& R.E. Eklund (eds.). Handbook of sport psychology (pp. 859-878). Hoboken, NJ: Wiley.

Mądrzycki, T. (1996). Osobowość jako system tworzacy i realizujacy plany [Personality as a system for creation and execution of plans]. Gdansk: GWP.

O’Brien, K.S., Hunter, J., Kypri, K. \& Ali, A. (2008). Gender equality in university sportspeople's drinking. Drug and Alcohol Review, 27, 659-665.

Pasman, L. \& Thompson, J.K. (1988). Body image and eating disturbance in obligatory runners, obligatory weightlifters, and sedentary individuals. International Journal of Eating Disorders, 7, 759769. doi: 10.1002/1098-108x(198811)7:6<759::aideat2260070605>3.0.co;2-g.

Robles, D.S. (2009). Thinness and beauty: when food becomes the enemy. International Journal of Research \& Review, 2, 16-30.

Staudinger, U.M., Fleeson, W. \& Batles, P.B. (1999). Predictors of subjective psychical health and global well-being: similarities and differences between the United States and Germany. Journal of Personality and Social Psychology, 76, 305-319.

Swami, V., Hadji-Michael, M. \& Furnham, A. (2008). Personality and individual difference correlates of positive body image. Body Image, 5, 322-325.

Tok, S. (2011). The big five personality traits and risky sport participation. Social Behaviour and Personality, 39, 1105-1112.

World Health Organization. (2012). Handbook for guideline development. Geneva: WHO.

Yusko, D.A., Buckman, J.F., White, H.R. \& Pandina, R.J. (2008). Alcohol, tobacco, illicit drugs, and performance enhancers: a comparison of use by college student athletes and nonathletes. Journal of American College Health, 57, 281-290.

Zaleski, Z. (1991). Psychologia zachowań celowych [Psychology of purposeful behavior]. Warszawa: Wydawnictwo Naukowe PWN.

Zawadzki, B., Strelau, J., Szczepaniak, P. \& Śliwińska, M. (1998). Inwentarz osobowości NEO-FFI Costy i McCrea. Adaptacja polska. Podręcznik [NEO-Five Factor Inventory NEO-FFI by Costa \& McCrea. Polish adpatation. Manual]. Warszawa: Pracownia Testów Psychologicznych Polskiego Towarzystwa Psychologicznego.

Zawadzki, B., Szczepaniak, P. \& Strelau, J. (1995). Diagnoza psychometryczna pięciu wielkich czynników osobowości: Adaptacja kwestionariusza NEO-FFI Costy i McCrae do warunków polskich [Psychometric diagnosis of the Big Five personality traits: Polish adaptation of the NEO-Five Factor Inventory (NEO-FFI) by Costa \& McCrea]. Studia Psychologiczne, 33, 189-255. 